\title{
PÓS-TRATAMENTO DE LIXIVIADO ESTABILIZADO POR CICLO COMPLETO, ADSORÇÃO E OXIDAÇÃO QUÍMICA
}

\section{POST-TREATMENT OF STABILIZED LANDFILL LEACHATE BY COMPLETE CYCLE, ADSORPTION AND CHEMICAL OXIDATION}

Marcella Yuri Almeida Sawaguchi ${ }^{1}$, Emily Giany Assunção ${ }^{2}$, Isabela Bruna de Tavares Machado Bolonhesi ${ }^{2}$, Gabriela Fonseca da Costa ${ }^{3}$, Vilson Gomes da Assunção Júnior ${ }^{4}$.

${ }^{1}$ Acadêmica de Engenharia Civil, Centro Universitário Filadélfia - UniFil.

E-mail: marcellasawaguchi@gmail.com

${ }^{2}$ Doutoranda em Engenharia Civil, Universidade Estadual de Londrina - UEL.

${ }^{3}$ Acadêmica de Engenharia Civil, Centro Universitário Filadélfia - UniFil.

4 Docente de Engenharia Civil, Centro Universitário Filadélfia - UniFil.

RESUMO - O lixiviado de aterro sanitário possui elevadas concentrações de matéria orgânica, compostos húmicos, nitrogenados, metais pesados e sais inorgânicos, requerendo tratamento adequado para que sua destinação final não cause danos ao meio ambiente. Estudos demonstram que o tratamento biológico não é suficiente, sendo necessário o pós-tratamento por associação de técnicas físico-químicas. Esse trabalho teve por objetivo avaliar a aplicação de técnicas complementares ao tratamento biológico, coagulação-floculaçãosedimentação (CFS) com cloreto férrico, oxidação por reação de Fenton (RF), seguidos de adsorção. Os pós-tratamentos CFS e RF empregados isoladamente apresentaram eficiência de remoção de matéria orgânica correlacionada à cor verdadeira de $>98,9 \%$ e $87,9 \%$, e $53,6 \%$ e $67 \%$ de DQO, enquadrando às exigências da Resolução CONAMA 357/05 e 430/11 de descarte em corpos hídricos. A adsorção após a reação de Fenton obteve remoção de $84,5 \%$ de matéria orgânica correlacionada à cor verdadeira e $67,0 \%$ de DQO. Já a adsorção após a CFS reduziu $76,9 \%$ da DQO. A CFS apresentou maior eficiência de remoção de matéria orgânica correlacionada à cor verdadeira, enquanto o tratamento com Fenton obteve maior eficiência de remoção dos parâmetros de NKT, N-amoniacal e DQO. O lixiviado tratado biologicamente apresentou baixa ecotoxicidade aguda ao organismo teste Artemia salina. Após a CFS e a adsorção, o baixo efeito tóxico do efluente foi mantido. Apesar da RF aumentar o efeito tóxico do efluente, após a adsorção não foi observado efeito tóxico para a associação de reação de Fenton e adsorção.

Palavras-chave: Chorume. Coagulação-floculação-sedimentação. Reação de Fenton; Cloreto férrico. Carvão ativado.

ABSTRACT - The leachate from landfill has high concentrations of organic matter, humic and nitrogenous compounds, heavy metals and inorganic salts, requiring proper treatment for its final discharge does not cause 
environmental damages. Studies had shown that biological treatment is not sufficient, requiring post-treatments by an association of physical-chemical techniques. This study aimed to evaluate the application of complementary techniques to the biological treatment such as coagulation-flocculationsedimentation (CFS) and Fenton's reaction oxidation (FR), followed by adsorption. The CFS with ferric chloride and FR post-treatments isolated had $>98,9 \%$ and $87,9 \%$, organic matter correlated with true color removal and $53,6 \%$ and $67,0 \%$ of COD removal, which meet with the requirements of CONAMA 357/05 e 430/11 for disposal in water bodies. The adsorption after Fenton reaction resulted in $84,5 \%$ organic matter correlated with true color removal and $67,0 \%$ of COD removal. Adsorption after coagulation-flocculationsedimentation was able to reduce $76,9 \%$ of COD. CFS showed higher removal efficiency of organic matter correlated to the true color, while RF obtained higher removal efficiency of NKT, N-ammoniacal and COD parameters. Biologically treated leachate had shown low levels of toxicity to Artemia salina. After CFS and adsorption, low toxicity level was remained in effluent. Despite of RF increased toxicity levels, after adsorption it was not observed toxic effects for the RF and adsorption association.

Keywords: Leachate. Coagulation-flocculation-sedimentation. Fenton Reaction. Ferric chloride. Activate carbon.

\section{INTRODUÇÃO}

Estima-se que $64,2 \%$ dos resíduos domiciliares brasileiros são dispostos em aterros sanitários (SNIS, 2017). Os resíduos dispostos em aterros sofrem degradação e solubilização gerando o lixiviado (TARTARI, 2005), um líquido escuro e turvo, com odor desagradável e composição complexa, contendo elevada concentração de sólidos suspensos, material orgânico (biodegradáveis e refratários), compostos húmicos, nitrogenados, metais pesados, sais inorgânicos, e cloretos (SERAFIM et al., 2003; KAWAHIGASHI et al., 2014; COSTA; ALFAIA; CAMPOS 2019).

A escolha de uma técnica de tratamento para lixiviados de aterro sanitário deve levar em consideração as características do líquido percolado, que podem variar conforme a localidade e tempo (aterros novos e aterros maduros), devendo-se avaliar, também, aspectos legais, custos e tecnologias disponíveis (QUEIROZ et al., 2011). O lixiviado estabilizado possui baixa biodegrabilidade devido à presença de constituintes biorefratários ou recalcitrantes (PEYRAVI et al., 2016). Neste caso, faz-se necessário o usode tratamentos conjuntos, físicos, químicos e biológicos, para seu tratamento adequado antes de ser descartado no corpo receptor. Por isso, é importante o estudo e a aplicação de técnicas que visem seu tratamento conforme legislação vigente (CASTILHOS JUNIOR; DALSASSO; ROHERS, 2010).

Dentre os tratamentos complementares utilizados podem ser citados a coagulaçãofloculação-sedimentação (CFS), oxidação por reação de Fenton (RF), e a adsorção. A CFS tem apresentado eficiência na remoção de matéria orgânica correlacionada à cor verdadeira, porém, não é eficaz para remoção da demanda química de oxigênio DQO recalcitrante (KAWAHIGASHI et al. 2014; MELLO et al., 2012). A reação de Fenton possui grande capacidade de remoção de cor verdadeira e DQO, (HUOSHENG et al., 2010; MALER et al., 2015; DA SILVA et al., 2006; SILVA et al., 2006). A adsorção em carvão ativado granular - CAG possui grande eficiência na remoção de DQO, cor verdadeira e carbono orgânico total (MENDES et al., 2013; KAWAHIGASHI et al., 2014).

Nessa perspectiva, este trabalho teve como objetivo avaliar a aplicabilidade da 
coagulação-floculação-sedimentação, da reação de Fenton, seguidos de adsorção como pós-tratamento de lixiviado de aterro sanitário em escala de bancada.

\section{METODOLOGIA}

\subsection{Lixiviado}

O lixiviado utilizado é proveniente de uma coleta única realizada no dia 26 de abril de 2019, no aterro do Limoeiro (Figura 1), localizado na cidade de Londrina-PR $O$ aterro foi desativado em 2010, sendo assim, seu lixiviado é caracterizado como estabilizado. $\mathrm{O}$ aterro conta com 2 lagoas de tratamento biológico e o lixiviado foi coletado após o tratamento. A caracterização do lixiviado tratado biologicamente foi realizada conforme os métodos analíticos descritos em APHA et al. (2018) para os parâmetros de cor verdadeira, cor aparente, $\mathrm{pH}$, turbidez, sólidos totais, sólidos totais fixos, NKT, Namoniacal e DQO, conforme Tabela 01.

Figura 1. Localização da coleta do lixiviado (Aterro do Limoeiro, Londrina - PR).

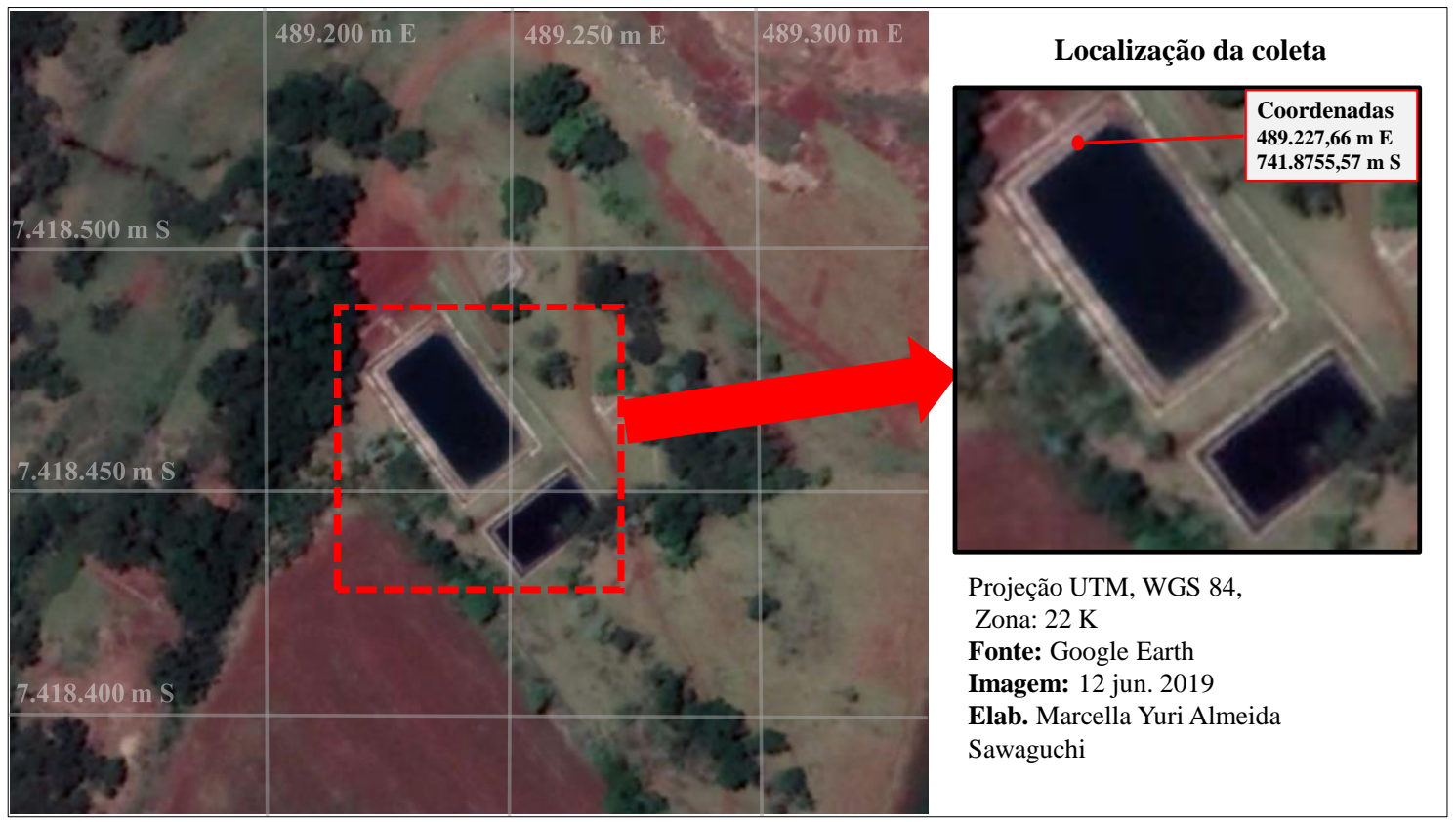

Fonte: Os autores, 2020.

Tabela 1. Parâmetros analisados e equipamentos utilizados de acordo com APHA (2018).

Parâmetros analisados Ref. APHA (2018) Equipamento (modelo/marca)

\begin{tabular}{|c|c|c|}
\hline $\mathrm{pH}$ & 4500 & pHmetro Gehaka PG2000 \\
\hline Turbidez (UNT) & $2130 \mathrm{~B}$ & Turbidímetro Hach $21000 Q$ \\
\hline $\begin{array}{l}\text { Cor aparente }(\mathrm{uH}), \\
\text { Cor verdadeira }(\mathrm{uH})\end{array}$ & $2120 \mathrm{C}$ & $\begin{array}{l}\text { Espectrofotômetro VIS - BEL } \\
\text { Photonics - V-M5 }\end{array}$ \\
\hline Sólidos totais e fixos $\left(\mathrm{mg} \cdot \mathrm{L}^{-1}\right)$ & $2540 \mathrm{~B}$ e $\mathrm{E}$ & $\begin{array}{c}\text { Mufla } 550^{\circ} \mathrm{C} \text { - EDG } 3 \text { P-S Estufa } \\
103^{\circ} \mathrm{C} \text { - QUIMIS }\end{array}$ \\
\hline DQO (mg.L $\left.{ }^{-1}\right)$ & $5220 \mathrm{C}$ & Digestor Hexis DRB 200 \\
\hline NKT (mg. $\left.\mathrm{L}^{-1}\right)$ & $4500-\mathrm{NH}_{2} \mathrm{~B}$ e $\mathrm{C}$ & $\begin{array}{l}\text { Destilador de Nitrogênio TE-0364 } \\
\text { Digestor de nitrogênio Tecnal TE-0365 }\end{array}$ \\
\hline $\mathrm{N}$-amoniacal (mg. $\left.\mathrm{L}^{-1}\right)$ & $4500-\mathrm{N} \mathrm{O}_{2} \mathrm{~B}$ & Destilador de Nitrogênio TE-0364 \\
\hline
\end{tabular}




\subsection{Coagulação-Floculação-Sedimentação}

Os experimentos de coagulação química, floculação e sedimentação foram realizados visando obter a melhor condição de coagulação química em relação à matéria orgânica, medida através da cor verdadeira. Para a coagulação foi preparada uma solução com concentração de $2.000 \mathrm{mg} \mathrm{L}^{-1}$ de $\mathrm{Fe}^{3+}$ utilizando uma solução comercial de cloreto férrico líquido com $39,4 \%$ de $\mathrm{FeCl}_{3} .6 \mathrm{H}_{2} \mathrm{O}, 1,42$ $\mathrm{kg} . \mathrm{L}^{-1}$ de massa específica e cor amarela.

Considerou-se as condições operacionais de um sistema de tratamento real em bateladas sequenciais. Para isso foi utilizado:

- Tempo de mistura rápida $\mathrm{T}_{\mathrm{mr}}=1,0 \mathrm{~min}$;

- Gradiente médio de velocidade de mistura rápida $\mathrm{G}_{\mathrm{mr}}=110 \mathrm{~s}^{-1}$;

- Tempo de floculação $\mathrm{T}_{\text {floc }}=20 \mathrm{~min}$;

- Gradiente de velocidade médio de floculação $\mathrm{G}_{\text {floc }}=20 \mathrm{~s}^{-1}$;

- Velocidade de sedimentação Vs $=0,117$ $\mathrm{cm} \cdot \mathrm{min}^{-1}$, que equivale a 0,5 hora de tempo de sedimentação;

- Jarro com capacidade de 2,0 L.

Para o ajuste de $\mathrm{pH}$ utilizou-se uma solução comercial de ácido clorídrico com 37\% em massa como acidificante, com uma massa específica de $1,187 \mathrm{~g} . \mathrm{L}^{-1}$ para preparação de solução com concentração de $73.000 \mathrm{mg} \mathrm{L}^{-1}$.

\subsection{Fenton}

O processo de oxidação com o reagente Fenton foi realizado por meio de reatores estáticos de bancada, com 6 jarros contendo $1 \mathrm{~L}$ de lixiviado cada, cujo $\mathrm{pH}$ foi ajustado com solução de ácido clorídrico. $\mathrm{O}$ tempo de mistura foi de $2 \mathrm{~h}$ para um gradiente de velocidade (G) de $156 \mathrm{~s}^{-1}$, e uma velocidade de sedimentação (Vs) de 0,058 $\mathrm{cm} \cdot \mathrm{min}^{-1}$, correspondente a $1 \mathrm{~h}$ de tempo de sedimentação. Após o tempo de sedimentação foram coletados $200 \mathrm{~mL}$ de cada jarro para avaliar os parâmetros de turbidez, cor verdadeira e $\mathrm{pH}$. Os reagentes utilizados foram:
- Solução de peróxido de hidrogênio $\mathrm{H}_{2} \mathrm{O}_{2}$ - (200 g. $\left.\mathrm{L}^{-1}\right)$;

- $\quad$ Solução de sulfato de ferro $-\mathrm{FeSO}_{4}$ (50g. L $\left.\mathrm{L}^{-1}\right)$.

O procedimento foi dividido em três etapas: I, II e III. Na etapa I foi avaliada a relação $\mathrm{H}_{2} \mathrm{O}_{2}$ e $\mathrm{Fe}^{2+}$, aplicando as relações mássicas de 1:1, 2:1, 3:1, 4:1, 5:1 e 6:1. Na etapa II utilizou-se a melhor relação $\mathrm{H}_{2} \mathrm{O}_{2}: \mathrm{Fe}^{2+}$ obtida na etapa I, variando-se as concentrações de $\mathrm{H}_{2} \mathrm{O}_{2}$, sendo elas 120,100 , $80,60,40$ e $20 \mathrm{mg} \cdot \mathrm{L}^{-1}$ de $\mathrm{H}_{2} \mathrm{O}_{2}$. Na etapa III verificou-se o melhor $\mathrm{pH}$ inicial, entre 4 e 5 , e - tempo necessário de sedimentação, utilizando o melhor resultado das etapas anteriores.

\subsection{Escolha do adsorvente}

Foram adquiridas amostras de 6 adsorventes disponíveis no mercado nacional com diferentes origens, matérias-primas, métodos de ativação para os carvões ativados e granulometria, sendo 4 carvões ativados e 2 zeólitas. Os carvões utilizados são provenientes de casca de coco, de osso, de mineral betuminoso e de endocarpo de coco babaçu. $O$ adsorvente mais adequado foi avaliado com relação à remoção de matéria orgânica correlacionada à cor verdadeira. As características dos adsorventes amostrados estão relacionadas na Tabela 2.

O experimento foi realizado por meio de reatores estáticos de bancada, Jartest, da marca Milan, utilizando $200 \mathrm{~mL}$ de lixiviado em béqueres, com finalidade de obter uma melhor homogeneização do lixiviado. Foram testadas proporções de 0,$5 ; 1 ; 2 ; 3,5$ e 5 g. L $^{-1}$ de adsorvente pulverizado, gradiente de mistura de $G=348 \mathrm{~s}^{-1}$ (120 rpm) e tempo de $\mathrm{T}=80 \mathrm{~min}$. Após o tempo de contato as amostras foram filtradas em membrana de fibra de vidro com $1,2 \mu \mathrm{m}$ de abertura para avaliação da cor verdadeira. 
Tabela 2. Características dos adsorventes amostrados

\begin{tabular}{|c|c|c|c|c|c|c|}
\hline & CAG 1 & CAG 2 & CAG 3 & CAG 4 & ZEO 1 & ZEO 2 \\
\hline matéria-prima & casca de coco & osso & $\begin{array}{c}\text { mineral } \\
\text { betuminoso }\end{array}$ & $\begin{array}{l}\text { endocarpo de } \\
\text { coco babaçu }\end{array}$ & natural & natural \\
\hline origem & vegetal & animal & mineral & vegetal & mineral & mineral \\
\hline ativação & física & física & química & física & - & - \\
\hline forma & granular & granular & granular & granular & granular & pulverizada \\
\hline $\begin{array}{l}\text { número de Iodo } \\
\qquad\left(\mathrm{mg}^{-\mathrm{g}^{-1}}\right)\end{array}$ & 995,04 & 200 & 993,8 & 812,2 & - & - \\
\hline $\mathrm{pH}$ & alcalino & alcalino & alcalino & alcalino & neutro & neutro \\
\hline
\end{tabular}

Fonte: Organizado pelos autores, 2020.

\subsection{Adsorção}

A melhor condição de oxidação pela reação de Fenton foi reproduzida em 6 jarros para obtenção de 6,0 L de efluente tratado, para realização da caracterização complementar e adsorção.

O sistema de adsorção utilizado com escoamento contínuo em escala de bancada, composto por:

- Bomba peristáltica com vazão préestabelecida de 0,24 mL. $\mathrm{min}^{-1}$, com tempo de contato de 10 min.;

- Um filtro com $10 \mathrm{~cm}$ de altura do adsorvente estabelecido;

- Vazão de $3,14 \mathrm{~mL} \cdot \mathrm{min}^{-1}$ e taxa de filtração de $14,39 \mathrm{~m}^{3} \cdot \mathrm{m}^{-1} \cdot \mathrm{d}^{-1}$.

Após a adsorção, o efluente foi analisado pelos parâmetros de $\mathrm{pH}$, cor verdadeira, turbidez a cada $1 \mathrm{~h}$ durante as três primeiras horas, após decorrer esse tempo o volume total de lixiviado adsorvido foi analisado por estes parâmetros, sólidos totais e fixos.

\subsection{Curva de Ruptura}

Para determinar a capacidade máxima de adsorção do adsorvente selecionado foi realizado a curva de ruptura utilizando o lixiviado tratado. A curva de ruptura foi realizada em escala de bancada, utilizando os seguintes materiais:
- Filtro com $10 \mathrm{~cm}$ de adsorvente no interior;

- Bomba peristáltica com vazão préestabelecida de 0,24 mL.min ${ }^{-1}$, com tempo de contato de $10 \mathrm{~min}$.;

- $\quad$ Vazão de 3,14 mL.min ${ }^{-1}$;

- Taxa de filtração de $14,39 \mathrm{~m}^{3} \cdot \mathrm{m}^{-2} \cdot \mathrm{d}^{-1}$;

- $\quad$ Massa de adsorvente: $17,81 \mathrm{~g}$.

$O$ efluente foi monitorado com coletas pontuais, com intervalos temporais de $15 \mathrm{~min}$ na primeira hora, e intervalos de 60 min em seguida, apenas em horário comercial até alcançar capacidade máxima do carvão. O encerramento das coletas ocorreu quando se atingiu $95 \%$ da relação $\mathrm{C}_{\mathrm{r}} / \mathrm{C}_{0}$ (cor aparente residual/cor aparente inicial).

\subsection{Bioensaio com Artemia salina}

A avaliação de toxicidade aguda do efluente tratado biologicamente e póstratado foi realizada com o microcrustáceo Artemia salina conforme prescrições da NBR 16.530 (ABNT, 2016). Para isso, foi preparada a solução salina com as concentrações normatizadas pela Petrobrás (1996) de $\mathrm{NaCl}$, $\mathrm{MgCl}_{2}, \mathrm{Na}_{2} \mathrm{SO}_{4}, \mathrm{CaCl}_{2} .2 \mathrm{H}_{2} \mathrm{O}$ e $\mathrm{KCl}$ em água deionizada, e ajuste de $\mathrm{pH}$ para 7,5.

Os cistos foram dispensados em um recipiente especial contendo orifícios de $2 \mathrm{~mm}$ de diâmetro, uniformemente distribuídos, parcialmente coberto, mantido 
na estufa a $25^{\circ} \mathrm{C}$ sob iluminação constante por $48 \mathrm{~h}$. Os náuplios utilizados foram aqueles que se deslocaram dentro do recipiente para a parte descoberta, isto é, sob a incidência da luz.

Os ensaios foram realizados em tubos de ensaio com 10 náuplios de Artemia salina em $10 \mathrm{~mL}$ de amostra, mantidos na capela a $25^{\circ} \mathrm{C}$ com iluminação constante. Cada diluição foi ensaiada em quadruplicata, sendo diluído em concentrações de 50, 60, $70,75,80$ e $90 \%$.

Os organismos presentes nos tubos de ensaio foram contabilizados após 24 e 48 horas, observando a letalidade/imortalidade dos organismos.

\section{RESULTADOS E DISCUSSÕES}

\subsection{Caracterização do lixiviado}

O lixiviado tratado biologicamente apresentou valores de $\mathrm{pH}$ de 7,63, cor verdadeira de $447,0 \mathrm{uH}, 280 \mathrm{mg} \cdot \mathrm{L}^{-1}$ de DQO, $50,2 \mathrm{mg} . \mathrm{L}^{-1}$ de NKT, e $47,0 \mathrm{mg} \cdot \mathrm{L}^{-1}$ de $\mathrm{N}$ amoniacal, o que remete às características de um lixiviado já estabilizado e bastante diluído, conforme apresentado na Tabela 08.

\subsection{Coagulação-Floculação-Sedimentação}

As Figuras 03 e 04 representam valores para remoção de cor verdadeira e de turbidez do efluente após o tratamento de CFS para diferentes valores de $\mathrm{pH}$ e dosagem de coagulantes.

Figura 03. Diagrama de coagulação-floculação-sedimentação do lixiviado pré-tratado biologicamente em relação à remoção de cor verdadeira.

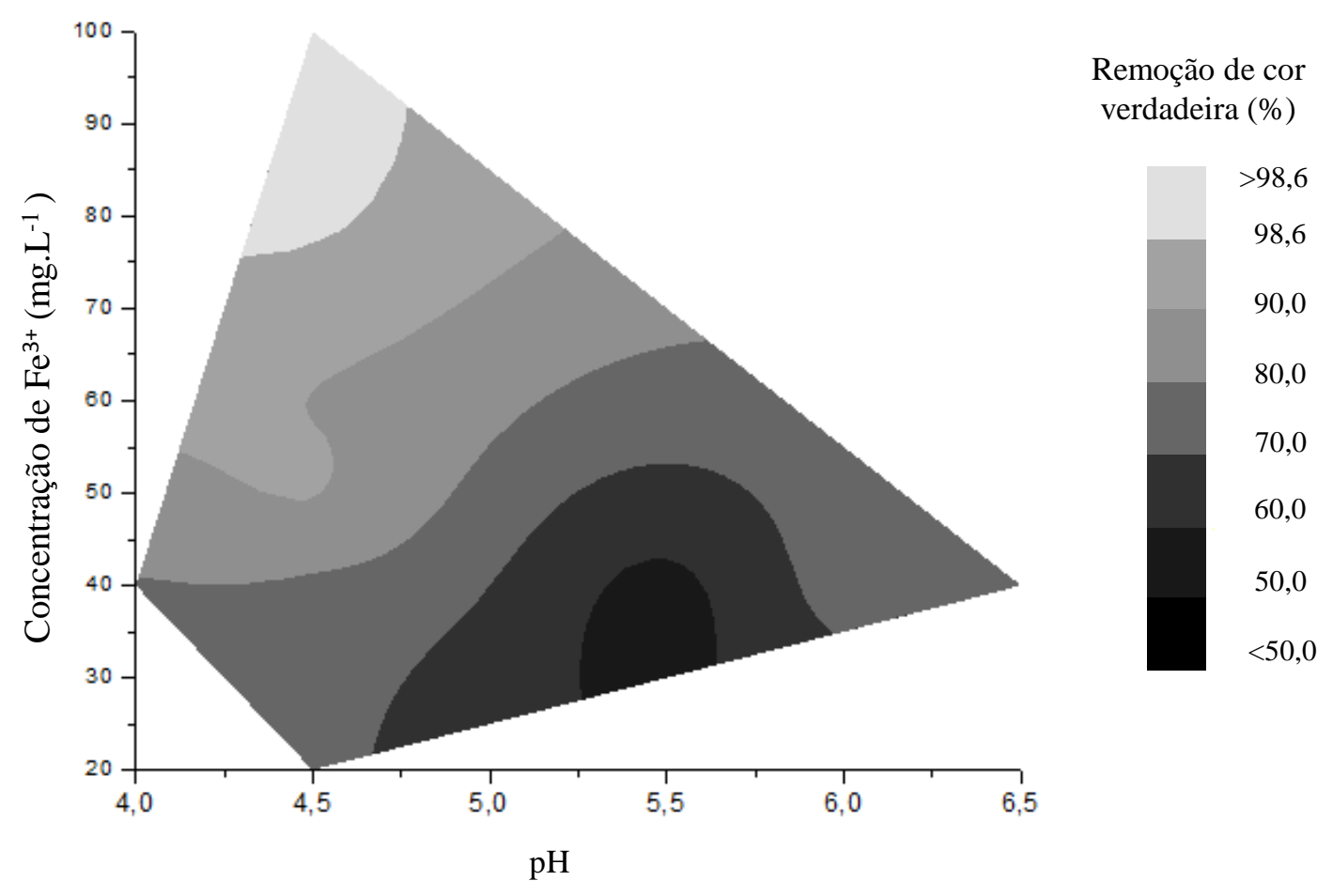

Fonte: Os autores, 2020. 
Figura 04. Diagrama de coagulação-floculação-sedimentação do lixiviado pré-tratado biologicamente em relação à remoção de turbidez.

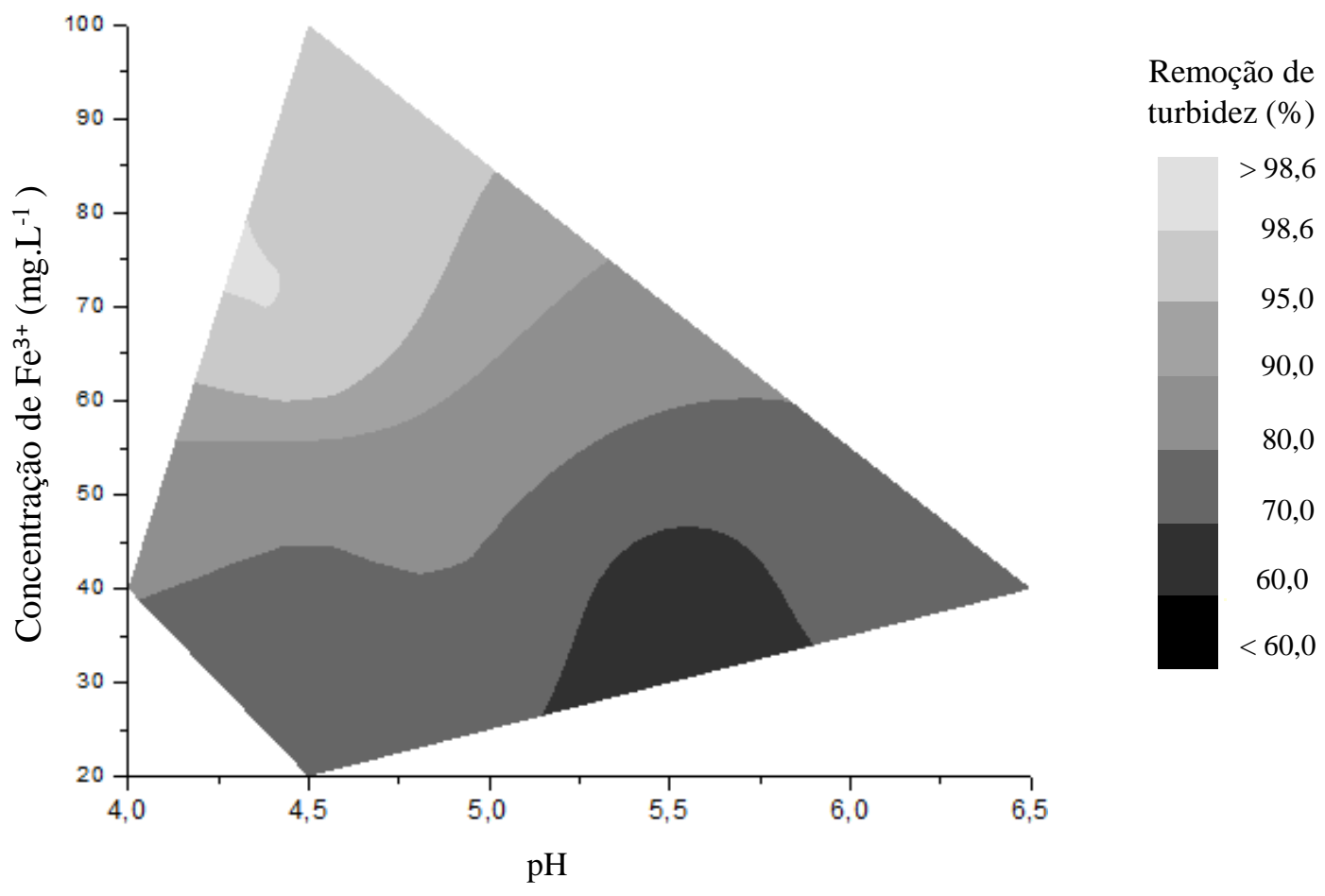

Fonte: Os autores, 2020.

Para a melhor condição de coagulação -floculação-sedimentação escolhida, com 80 $\mathrm{mg} \mathrm{L}^{-1}$ de $\mathrm{Fe}^{3+}$ a um $\mathrm{pH}$ de 4,5 , foi possível alcançar remoções de turbidez e cor verdadeira correspondentes a $97,9 \%$ e $>98,9 \%$ respectivamente. Esta condição resultou em reduções de $76,5 \%$ de NKT, $53,6 \%$ de DQO e $83,4 \%$ de $\mathrm{N}$-amoniacal. Mendes et al. (2013) obtiveram remoção de $96,0 \%$ na DQO, porém o efluente estudado pelos autores apresentava DQO inicial de $2.022 \mathrm{mg} \mathrm{O}_{2} \mathrm{~L}^{-1}$, superior à do lixiviado estudado neste trabalho, com DQO inicial de $280 \mathrm{mg} \mathrm{O}_{2} \mathrm{~L}^{-1}$.

Resultados semelhantes com relação à remoção de matéria orgânica correlacionada à cor verdadeira foram obtidos por Kawahigashi et al. (2014) que obtiveram remoção de $96,0 \%$ de cor verdadeira com a aplicação de $250 \mathrm{mg} \mathrm{L}^{-1}$ de $\mathrm{Fe}^{3+}$ como pós-tratamento de lixiviado estabilizado. Maler et al. (2015) aplicaram $350 \mathrm{mg} \mathrm{L}^{-1}$ de $\mathrm{Fe}^{3+}$ a um $\mathrm{pH} 4$ como pós tratamento do lixiviado estabilizado e obtiveram $96,0 \%$ de remoção de cor verdadeira. Felici et al. (2013) utilizaram 300 $\mathrm{mg} \mathrm{L}^{-1}$ de $\mathrm{Fe}^{3+}$ para remover $80 \%$ de DQO, porém o lixiviado estudado pelos autores possuía DQO inicial de $2.973 \mathrm{mg} \mathrm{O}_{2} \mathrm{~L}^{-1}$.

Este trabalho utilizou dosagem de $\mathrm{Fe}^{3+}$ inferior aos demais trabalhos relacionados na Tabela 03, devido ao lixiviado estabilizado tratado biologicamente utilizado neste estudo apresentar características de um lixiviado bastante diluído. 
Tabela 03. Resumo das eficiências de remoção após o tratamento de coagulação-floculação-sedimentação.

\begin{tabular}{|c|c|c|c|c|c|c|}
\hline Etapa de tratamento & Características iniciais & Coagulante & Dosagem & $\mathbf{p H}$ & Eficiência de remoção & Referência \\
\hline $\begin{array}{l}\text { Pós-tratamento ao } \\
\text { tratamento biológico }\end{array}$ & $\begin{array}{c}\mathrm{pH} \mathrm{8,3} \\
\mathrm{DQO} 6707 \mathrm{mg} \mathrm{O}_{2} \mathrm{~L}^{-1}\end{array}$ & $\begin{array}{l}\text { Cloreto } \\
\text { férrico }\end{array}$ & $800 \mathrm{mg} \mathrm{L}^{-1} \mathrm{Fe}^{3+}$ & 4 & DQO $>90 \%$ & $\begin{array}{l}\text { QUEIROZ et al., } \\
2011\end{array}$ \\
\hline $\begin{array}{l}\text { Pós-tratamento ao } \\
\text { tratamento biológico }\end{array}$ & $\begin{array}{c}\text { pH 9,1; Cor verdaddeira } 3386 \text { uH } \\
\text { DQO } 2022 \mathrm{mg} \mathrm{O}_{2} \mathrm{~L}^{-1}\end{array}$ & $\begin{array}{l}\text { Cloreto } \\
\text { férrico }\end{array}$ & $250 \mathrm{mg} \mathrm{L}^{-1} \mathrm{Fe}^{3+}$ & 4 & $\begin{array}{c}\text { Cor verdadeira } 96 \% \\
\text { DQO } 85 \% .\end{array}$ & $\begin{array}{l}\text { MENDES et al., } \\
2013 \\
\end{array}$ \\
\hline $\begin{array}{l}\text { Pós-tratamento ao } \\
\text { tratamento biológico }\end{array}$ & $\begin{array}{c}\mathrm{pH} 8,45 \text {; Cor verdadeira } 5110 \mathrm{uH} \text {; } \\
\mathrm{DQO} 2973 \mathrm{mgO}_{2} \mathrm{~L}^{-1}\end{array}$ & $\begin{array}{l}\text { Cloreto } \\
\text { férrico }\end{array}$ & $300 \mathrm{mg} \mathrm{L}^{-1} \mathrm{Fe}^{3+}$ & 3 & $\begin{array}{c}\text { Cor verdadeira } 96,4 \% \\
\text { DQO } 80,4 \% \\
\end{array}$ & FELICl et al., 2013 \\
\hline Tratamento & $\begin{array}{l}\mathrm{pH} 7,1 ; \operatorname{Cor}(\mathrm{Abs}-425 \mathrm{~nm}) 2,14 \\
\mathrm{DQO}: 4845 \mathrm{mg} \mathrm{L}^{-1} \text { - primavera }\end{array}$ & $\begin{array}{l}\text { Cloreto } \\
\text { férrico }\end{array}$ & $2,4 \mathrm{~g} \mathrm{~L}^{-1} \mathrm{FeCl}_{3}$ & 9,5 & DQO $40 \%$ & GUNES, 2014 \\
\hline Tratamento & $\begin{array}{c}\text { pH 7,8; Cor (Abs-425nm) 2,14 } \\
\text { DQO: } 4400 \mathrm{mg} \mathrm{O}_{2} \mathrm{~L}^{-1} \text { - verão }\end{array}$ & $\begin{array}{l}\text { Cloreto } \\
\text { férrico }\end{array}$ & $2,4 \mathrm{~g} \mathrm{~L}^{-1} \mathrm{FeCl}_{3}$ & 9,5 & DQO 35\% & GUNES, 2014 \\
\hline $\begin{array}{l}\text { Pós-tratamento ao } \\
\text { tratamento biológico }\end{array}$ & $\begin{array}{c}\text { pH 9,7; Cor verdadeira } 3386 \mathrm{uH} \\
\text { DQO } 2022 \mathrm{mg} \mathrm{O}_{2} \mathrm{~L}^{-1}\end{array}$ & $\begin{array}{l}\text { Cloreto } \\
\text { férrico }\end{array}$ & $250 \mathrm{mg} \mathrm{L}^{-1} \mathrm{Fe}^{3+}$ & 4 & $\begin{array}{c}\text { Cor verdadeira } 96 \% \\
\text { DQ0 } 85 \%\end{array}$ & $\begin{array}{c}\text { KAWAHIGASHI et } \\
\text { al., } 2014\end{array}$ \\
\hline Tratamento & $\begin{array}{c}\text { pH 9,1; Cor verdadeira } 4180 \mathrm{uH} \\
\text { DQO } 1819 \mathrm{mg} \mathrm{O}_{2} \mathrm{~L}^{-1}\end{array}$ & $\begin{array}{l}\text { Cloreto } \\
\text { férrico }\end{array}$ & $350 \mathrm{mg} \mathrm{L}^{-1} \mathrm{Fe}^{3+}$ & 4 & $\begin{array}{c}\text { Cor verdadeira } 96 \% \\
\text { DQO } 78 \% \\
\end{array}$ & $\begin{array}{c}\text { MALER et al., } \\
2015 \\
\end{array}$ \\
\hline Tratamento & $\begin{array}{c}\mathrm{pH} 8,5 \\
\text { DQO } 1031 \mathrm{mg} \mathrm{O}_{2} \mathrm{~L}^{-1}\end{array}$ & $\begin{array}{l}\text { Cloreto } \\
\text { férrico }\end{array}$ & $300 \mathrm{mg} \mathrm{L}^{-1} \mathrm{Fe}^{3+}$ & 4 & $\begin{array}{c}\text { DQO } 22,9 \% \\
\text { COT } 64 \%\end{array}$ & $\begin{array}{l}\text { VASCONCELOS et } \\
\text { al., } 2017\end{array}$ \\
\hline $\begin{array}{l}\text { Pós-tratamento ao } \\
\text { tratamento biológico }\end{array}$ & $\begin{array}{c}\text { pH 7,6; Cor verdadeira } 447 \mathrm{uH} \\
\text { DQO } 280 \mathrm{mg} \mathrm{O}_{2} \mathrm{~L}^{-1}\end{array}$ & $\begin{array}{l}\text { Cloreto } \\
\text { férrico }\end{array}$ & $80 \mathrm{mg} \mathrm{L}^{-1} \mathrm{Fe}^{3+}$ & 4,5 & $\begin{array}{c}\text { Cor verdadeira }>98,9 \% \\
\text { DQO } 53,6 \%\end{array}$ & $\begin{array}{l}\text { Este trabalho, } \\
2020\end{array}$ \\
\hline
\end{tabular}

Fonte: Organizado pelos autores, 2020.

\subsection{Fenton}

\subsubsection{Etapa I}

$O$ ensaio de avaliação da melhor proporção de $\mathrm{H}_{2} \mathrm{O}_{2}: \mathrm{Fe}^{2+}$ para reação de Fenton, utilizou as proporções 1:1, 2:1, 3:1, $4: 1, \quad 5: 1$ e $6: 1$, e seus resultados são apresentados na Tabela 4. Até a proporção 4:1 houve um aumento na eficiência remoção de matéria orgânica correlacionada à cor verdadeira conforme o aumento da proporção $\mathrm{H}_{2} \mathrm{O}_{2}: \mathrm{Fe}^{2+}$, a partir dessa concentração não houve aumento na eficiência.
A relação $\mathrm{H}_{2} \mathrm{O}_{2}: \mathrm{Fe}^{2+}$ define se a remoção da matéria orgânica ocorre por meio da coagulação ou oxidação. Quanto menor a relação entre os dois reagentes maior será a participação da coagulação e menor de oxidação na remoção da matéria orgânica (RODRIGUES; LOPES, 2013). O excesso de íons de $\mathrm{Fe}^{2+}$ favorece a ocorrência de remoção de matéria orgânica por oxidação (DENG, 2007; KANG; HWANG, 2000).

Tabela 4. Parâmetros de operação e valores residuais dos parâmetros de desempenho após o ensaio realizado na Etapa I.

Parâmetros de operação

Valores residuais dos parâmetros de desempenho

\begin{tabular}{|c|c|c|c|c|c|c|c|c|}
\hline $\begin{array}{c}\text { Dosagem } \\
\text { de } \mathrm{H}_{2} \mathrm{O}_{2} \\
\left(\mathrm{mg} \cdot \mathrm{L}^{-1}\right)\end{array}$ & $\begin{array}{c}\text { Dosagem } \\
\text { de } \mathrm{Fe}^{2+} \\
\left(\mathrm{mg} \cdot \mathrm{L}^{-1}\right)\end{array}$ & $\mathrm{H}_{2} \mathrm{O}_{2}: \mathrm{Fe}^{2+}$ & pH inicial & Lodo (\%) & $\begin{array}{c}\text { Turbidez } \\
\text { (UNT) }\end{array}$ & $\begin{array}{c}\text { Cor } \\
\text { verdadeira } \\
\quad(\mathrm{uH})\end{array}$ & $\begin{array}{c}\text { Remoção } \\
\text { de cor } \\
\text { verdadeira } \\
(\%)\end{array}$ & pH final \\
\hline 100,0 & 100,0 & $1: 1$ & 4,0 & 2,7 & 4,0 & 130,0 & 70,9 & 3,1 \\
\hline 100,0 & 50,0 & $2: 1$ & 4,0 & 2,7 & 4,8 & 125,4 & 71,9 & 3,2 \\
\hline 100,0 & 33,3 & $3: 1$ & 4,0 & 5,3 & 4,2 & 100,3 & 77,6 & 3,3 \\
\hline 100,0 & 25,0 & $4: 1$ & 4,0 & 4,0 & 3,7 & 100,3 & 77,6 & 3,4 \\
\hline 100,0 & 20,0 & $5: 1$ & 4,0 & 5,3 & 3,4 & 113,0 & 74,7 & 3,5 \\
\hline 100,0 & 16,7 & $6: 1$ & 4,0 & 4,0 & 3,0 & 130,0 & 70,9 & 3,5 \\
\hline
\end{tabular}

Fonte: Os autores, 2020.

É esperado que quanto maior a concentração de $\mathrm{H}_{2} \mathrm{O}_{2}$, maior a remoção dos compostos orgânicos (MORAVIA; LANG; AMARAL 2011; RODRIGUES; LOPES,2013) porém, o $\mathrm{H}_{2} \mathrm{O}_{2}$ não deve estar em excesso, pois pode diminuir a eficiência do tratamento, já que grandes dosagens para $\mathrm{Fe}^{2+}$ podem aumentar a salinidade e a 
condutividade do efluente tratado (DENG 2007; YANYU et al., 2010; MORAVIA; LANGE; AMARAL, 2011).

As proporções com melhor eficiência para a remoção de matéria orgânica correlacionada à cor verdadeira foram as de 3:1 e 4:1 de $\mathrm{H}_{2} \mathrm{O}_{2}: \mathrm{Fe}^{2+}$ com $78 \%$ de remoção, aproximadamente. A proporção escolhida foi 3:1, pois além de apresentar menor turbidez residual, utiliza menor quantidade de produtos químicos.

\subsubsection{Etapa II}

Nesta etapa, variou-se as dosagens iniciais de $\mathrm{H}_{2} \mathrm{O}_{2}$, visando obter a menor quantidade necessária para o tratamento do efluente. Os valores para lodo, cor verdadeira, turbidez e pH estão apresentados na Tabela 5 . Em relação à remoção de cor verdadeira obteve-se até $78,5 \%$ de remoção para a concentrações de $120 \mathrm{mg} \cdot \mathrm{L}^{-1}$ de $\mathrm{H}_{2} \mathrm{O}_{2}$ para uma relação de $3: 1$ de $\mathrm{H}_{2} \mathrm{O}_{2}: \mathrm{Fe}^{2+}$. Os valores de turbidez variaram de 3,1 a 12,4 UNT.

Dentre as dosagens empregadas nessa etapa a escolhida foi a de $60 \mathrm{mg} \mathrm{L}^{-1}$ de $\mathrm{H}_{2} \mathrm{O}_{2}$ e de $20 \mathrm{mg} \mathrm{L}^{-1}$ de $\mathrm{Fe}^{2+}$, em razão de utilizar menor quantidade de químico para seu tratamento, com uma remoção de matéria orgânica correlacionada à cor verdadeira de $71 \%$ e uma turbidez 7,9 UNT. A partir dessa dosagem, os ganhos de eficiência não foram substanciais.

Tabela 5. Parâmetros de operação e caracterização de desempenho após a Etapa II.

Parâmetros de operação

Valores residuais dos parâmetros de desempenho

\begin{tabular}{ccccccccc}
\hline $\begin{array}{c}\text { Dosagem } \\
\text { de } \mathbf{H}_{2} \mathbf{O}_{2} \\
\left(\mathbf{m g} \cdot \mathbf{L}^{-1}\right)\end{array}$ & $\begin{array}{c}\text { Dosagem } \\
\text { de } \mathrm{Fe}^{2+} \\
\left(\mathbf{m g} \cdot \mathbf{L}^{-1}\right)\end{array}$ & $\mathbf{H}_{\mathbf{2}} \mathbf{O}_{\mathbf{2}}: \mathrm{Fe}^{2+}$ & $\mathbf{p H}$ inicial & Lodo $(\%)$ & $\begin{array}{c}\text { Turbidez } \\
\text { (UNT) }\end{array}$ & $\begin{array}{c}\text { Cor } \\
\text { verdadeira } \\
\text { (uH) }\end{array}$ & $\begin{array}{c}\text { Remoção } \\
\text { de cor } \\
\text { verdadeira } \\
(\%)\end{array}$ & pH final \\
\hline 120,0 & 40,0 & $3: 1$ & 4,0 & 4,0 & 3,1 & 96,1 & 78,5 & 3,2 \\
100,0 & 33,3 & $3: 1$ & 4,0 & 5,3 & 3,6 & 100,3 & 77,6 & 3,0 \\
80,0 & 26,7 & $3: 1$ & 4,0 & 4,0 & 4,2 & 100,3 & 77,6 & 3,1 \\
60,0 & 20,0 & $3: 1$ & 4,0 & 5,3 & 7,9 & 129,5 & 71,0 & 3,3 \\
40,0 & 13,3 & $3: 1$ & 4,0 & 4,0 & 8,5 & 167,1 & 62,6 & 3,4 \\
20,0 & 6,7 & $3: 1$ & 4,0 & 1,3 & 12,4 & 246,5 & 44,9 & 3,7 \\
\hline
\end{tabular}

Fonte: Os autores, 2020.

\subsubsection{Etapa III}

Nesta última etapa foi analisada a proporção 3:1 para uma dosagem de $60 \mathrm{mg} \mathrm{L}^{-}$ ${ }^{1}$ de $\mathrm{H}_{2} \mathrm{O}_{2}$ e $20 \mathrm{mg} \mathrm{L}^{-1}$ de $\mathrm{Fe}^{2+}$ com um tempo de sedimentação de 0,5 e 1 hora e pH de 4,0 e 5,0 .

Conforme a Tabela 6, o tempo de sedimentação - 0,5 e 1 hora - não interferiu significativamente na remoção de cor verdadeira, mas contribuíram significativamente na redução da turbidez.

Para o $\mathrm{pH} 4$, a redução na turbidez de 30 min para 1 hora foi de $2,8 \%$, ou seja, um maior tempo de sedimentação de $1 \mathrm{~h}$ e $\mathrm{pH}$ inicial de reação de 4,0.
A partir dos resultados obtidos nas Etapas I, II, e III, foi determinada como a melhor condição de oxidação a dosagem de $60 \mathrm{mg} . \mathrm{L}^{-1}$ de $\mathrm{H}_{2} \mathrm{O}_{2}, 20 \mathrm{mg} . \mathrm{L}^{-1}$ de $\mathrm{Fe}^{2+}$ a um pH de 4, como apresentado na Tabela 09.

O pós-tratamento por reação de Fenton atingiu remoção de $67,0 \%$ de DQO, $87,4 \%$ de $\mathrm{N}$-amoniacal, $78,1 \%$ de NKT e $87,8 \%$ de matéria orgânica correlacionada à cor verdadeira. Como observado na Tabela 7, resultados semelhantes foram obtidos por Rodrigues e Lopes (2013), com 70\% de remoção de DQO utilizando uma relação $\mathrm{H}_{2} \mathrm{O}_{2} / \mathrm{Fe}^{2+}$ de 4 e $240 \mathrm{mM}$ de $\mathrm{H}_{2} \mathrm{O}_{2}$ aplicado no pós tratamento e Maler et al. (2016) com dosagem de $800 \mathrm{mgL}^{-1}$ de $\mathrm{H}_{2} \mathrm{O}_{2}$ e $700 \mathrm{mgL}^{-1}$ 
de $\mathrm{Fe}^{2+}$ atingindo remoções de $71,0 \%$ de DQO e 92,0\% de matéria orgânica correlacionada à cor verdadeira.

Tabela 6. Parâmetros de operação e valores residuais dos parâmetros de desempenho após Etapa III.

\begin{tabular}{|c|c|c|c|c|c|c|c|c|c|}
\hline \multirow[b]{2}{*}{$\begin{array}{c}\text { Tempo de } \\
\text { sedimenta } \\
\text { ção (h) }\end{array}$} & \multicolumn{4}{|c|}{ Parâmetros de operação } & \multicolumn{5}{|c|}{ Valores residuais dos parâmetros de desempenho } \\
\hline & $\begin{array}{c}\text { Dosagem } \\
\text { de } \mathrm{H}_{2} \mathrm{O}_{2} \\
\left(\mathrm{mg}^{-\mathrm{L}^{-1}}\right)\end{array}$ & $\begin{array}{c}\text { Dosagem } \\
\text { de } \mathrm{Fe}^{2+} \\
\left(\mathrm{mg} \cdot \mathrm{L}^{-1}\right)\end{array}$ & $\mathrm{H}_{2} \mathrm{O}_{2}: \mathrm{Fe}^{2+}$ & pH inicial & Lodo (\%) & $\begin{array}{c}\text { Turbidez } \\
\text { (UNT) }\end{array}$ & $\begin{array}{c}\text { Cor } \\
\text { verdadeira } \\
\text { (uH) }\end{array}$ & $\begin{array}{c}\text { Remoção } \\
\text { de cor } \\
\text { verdadeira } \\
(\%) \\
\end{array}$ & pH final \\
\hline 0,5 & 60,0 & 20,0 & \multirow{2}{*}{$3: 1$} & \multirow{2}{*}{4,0} & 2,7 & 12,7 & 142,1 & 68,2 & 3,1 \\
\hline 1,0 & 60,0 & 20,0 & & & 4,0 & 7,8 & 129,5 & 71,0 & 2,9 \\
\hline 0,5 & 60,0 & 20,0 & \multirow{2}{*}{$3: 1$} & \multirow{2}{*}{5,0} & 1,3 & 17,5 & 158,8 & 64,5 & 3,0 \\
\hline 1,0 & 60,0 & 20,0 & & & 2,7 & 11,8 & 142,1 & 68,2 & 3,1 \\
\hline
\end{tabular}

Fonte: Os autores, 2020.

Tabela 07. Resultados obtidos na literatura para tratamento de lixiviado pós-tratamento por Fenton

\begin{tabular}{|c|c|c|c|c|c|}
\hline Etapa de tratamento & Características iniciais & Dosagem & pH & Eficiência de remoção & Referência \\
\hline Tratamento & $\begin{array}{c}\mathrm{pH} \mathrm{7,7} \\
\mathrm{DQO} 1800 \mathrm{mg} \mathrm{O}_{2} \mathrm{~L}^{-1}\end{array}$ & $\begin{array}{l}3,6 \mathrm{gL}^{-1} \mathrm{H}_{2} \mathrm{O}_{2} \\
1,8 \mathrm{gL}^{-1} \mathrm{FeSO}_{4}\end{array}$ & 4 & DQO 80\% & $\begin{array}{l}\text { LANGE et al., } \\
2006\end{array}$ \\
\hline Tratamento & $\mathrm{DQO} 2807 \mathrm{mg} \mathrm{O}_{2} \mathrm{~L}^{-1}$ & $\begin{array}{l}3000 \mathrm{mgL}^{-1} \mathrm{H}_{2} \mathrm{O}_{2} \\
150 \mathrm{mgL}-1 \mathrm{Fe}\end{array}$ & 2 & DQO 88,43\% & $\begin{array}{l}\text { SILVA et al., } \\
2006\end{array}$ \\
\hline Tratamento & $\begin{array}{c}\mathrm{pH} 8,5 \\
\mathrm{DQO} 8000 \mathrm{mg} \mathrm{O}_{2} \mathrm{~L}^{-1}\end{array}$ & $3,0-3,5 \mathrm{~g} \cdot \mathrm{L}^{-1} \mathrm{H}_{2} \mathrm{O}_{2}$ & 8 & DQO 33\% & $\begin{array}{l}\text { KURNIAWAN } \\
\text { et al, } 2009\end{array}$ \\
\hline Tratamento & $\begin{array}{c}\text { pH 8,3; Cor verdadeira } 487 \mathrm{uH} \\
\mathrm{DQO} 2354 \mathrm{mg} \mathrm{O}_{2} \mathrm{~L}^{-1}\end{array}$ & $\begin{array}{c}\text { DQO: } \mathrm{H}_{2} \mathrm{O}_{2}: \mathrm{FeSO}_{4} 7 \mathrm{H}_{2} \mathrm{O} \\
=10: 6: 1\end{array}$ & 3,8 & $\begin{array}{c}\text { Cor verdadeira } 76,4 \% \\
\text { DQO } 76,7 \% \\
\end{array}$ & $\begin{array}{l}\text { MORAVIA et } \\
\text { al., } 2011\end{array}$ \\
\hline $\begin{array}{l}\text { Pós-tratar } \\
\text { tratamento }\end{array}$ & $\begin{array}{c}\mathrm{pH} 3,2-5,4 \\
\text { DQO 613-1996 } \mathrm{mg} \mathrm{O}_{2} \mathrm{~L}^{-1}\end{array}$ & $\begin{array}{l}\mathrm{H}_{2} \mathrm{O}_{2} / \mathrm{Fe}^{2+}=4 \\
\left(240 \mathrm{mM} \mathrm{H}_{2} \mathrm{O}_{2}\right)\end{array}$ & - & DQO 70\% & $\begin{array}{c}\text { RODRIGUES et } \\
\text { al., } 2013\end{array}$ \\
\hline Tratamento & $\mathrm{DQO} 1392 \mathrm{mg} \mathrm{O}_{2} \mathrm{~L}^{-1}$ & $\begin{array}{c}\mathrm{Fe}^{2+}: \mathrm{H}_{2} \mathrm{O}_{2}=1: 5 \\
\left(2958 \mathrm{mgL}^{-1} \mathrm{H}_{2} \mathrm{O}_{2}\right)\end{array}$ & 3 & DQO 56\% & $\begin{array}{l}\text { DA COSTA et } \\
\text { al., } 2015\end{array}$ \\
\hline $\begin{array}{l}\text { Pós-tratamento ao } \\
\text { tratamento biológico }\end{array}$ & $\begin{array}{c}\text { pH 9,1; Cor verdadeira } 4180 \mathrm{uH} \\
\text { DQO } 1819 \mathrm{mg} \mathrm{O}_{2} \mathrm{~L}^{-1}\end{array}$ & $\begin{array}{l}800 \mathrm{mg} \mathrm{L}^{-1} \mathrm{H}_{2} \mathrm{O}_{2} \\
700 \mathrm{mg} \mathrm{L}^{-1} \mathrm{Fe}^{2+}\end{array}$ & 4 & $\begin{array}{c}\text { Cor verdadeira } 92 \% \\
\text { DQO } 71 \% \\
\end{array}$ & $\begin{array}{l}\text { MALER et al., } \\
2016 \\
\end{array}$ \\
\hline Tratamento & $\mathrm{DQO} 2490 \mathrm{mg} \mathrm{O}_{2} \mathrm{~L}^{-1}$ & Fe: $\mathrm{H}_{2} \mathrm{O}_{2}=1: 3$ & 3 & DQO 78,42\% & $\begin{array}{l}\text { VASCONCELOS } \\
\text { et al., } 2017\end{array}$ \\
\hline $\begin{array}{l}\text { Pós-tratamento ao } \\
\text { tratamento biológico }\end{array}$ & $\begin{array}{c}\text { pH 7,6; Cor verdadeira } 447 \text { uH } \\
\text { DQO } 280 \mathrm{mg} \mathrm{O}_{2} \mathrm{~L}^{-1} \\
\end{array}$ & $\begin{array}{l}60 \mathrm{mg} \mathrm{L}^{-1} \mathrm{H}_{2} \mathrm{O}_{2} \\
20 \mathrm{mg} \mathrm{L}^{-1} \mathrm{FeSO}_{2}\end{array}$ & 4 & $\begin{array}{c}\text { Cor verdadeira } 87,8 \% \\
\text { DQO } 67 \% \\
\end{array}$ & $\begin{array}{c}\text { Este trabalho, } \\
2020 \\
\end{array}$ \\
\hline
\end{tabular}

Fonte: Organizado pelos autores, 2020.

\subsection{Seleção do adsorvente}

A escolha do adsorvente foi fundamentada na remoção de matéria orgânica correlacionada à cor verdadeira. Os resultados de cor verdadeira residual dos sobrenadantes submetidos à adsorção estão representados na Figura 2.

Na figura 2 é possível comparar a cor verdadeira residual após a adsorção para os diferentes adsorventes e concentração de adsorventes em g. $\mathrm{L}^{-1}$. Os carvões ativados apresentaram resultados melhores que as zeólitas, uma vez que as zeólitas amostradas apresentaram um aumento na cor verdadeira do efluente.
Os melhores resultados obtidos foram para os CAGs 3 e 2, que apresentaram respectivamente até $82,0 \%$ e $>98,9 \%$ de remoção de cor verdadeira para concentração de 5 g. $\mathrm{L}^{-1}$ de adsorvente. Em relação aos outros adsorventes amostrados, - CAG 2, proveniente de osso foi o que apresentou menor valor de cor verdadeira residual em todas as concentrações, atingindo cor residual inferior ao limite de quantificação do método (<L.Q.) para concentração de 5 g. L $^{-1}$ de adsorvente. Pozzetti et al. (2013) obtiveram cor verdadeira residual abaixo de $40 \mathrm{uH}$ utilizando carvão proveniente do osso. 
Porém Kawahigashi et al. (2014) não obtiveram resultados com eficiência relevante para carvão com mesma origem.

$O$ adsorvente selecionado foi o CAG 2, de origem animal, proveniente de osso, com índice de lodo de $200 \mathrm{mg} \mathrm{g}^{-1}$, pois para a concentração de $5 \mathrm{~g} \mathrm{~L}^{-1}$ apresentou remoção de $98,9 \%$ de matéria orgânica correlacionada à cor verdadeira.

Figura 2. Cor verdadeira residual do lixiviado após o ensaio para seleção do adsorvente utilizando diferentes tipos de carvão e zeólita

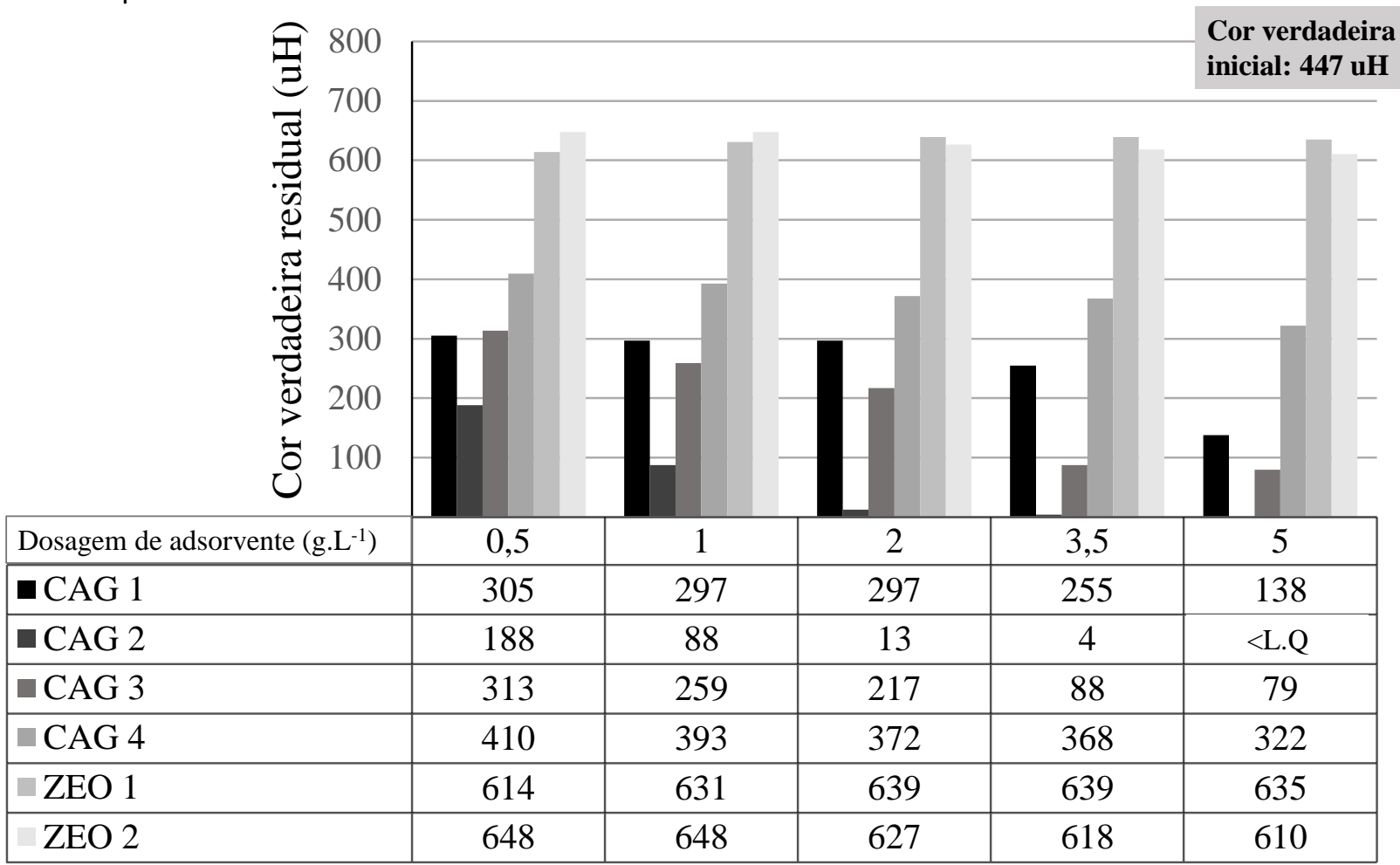

Fonte: Os autores, 2020.

\subsection{Adsorção}

O experimento de pós-tratamento por adsorção foi realizado apenas com o adsorvente pré-selecionado CAG 2, visando a adsorção da matéria orgânica residual recalcitrante que não foi removida pelos póstratamentos RF e CFS, nas melhores condições estabelecidas anteriormente. A
Tabela 08 apresenta os resultados obtidos após o pós-tratamento por adsorção.

Após a adsorção, o efluente póstratado por reação de Fenton e por coagulação-floculação-sedimentação obteve redução no $\mathrm{N}$-amoniacal de $66,0 \%$ e $74,0 \%$ respectivamente. A Figura 05 demonstra o efluente tratado biologicamente, e após cada etapa de tratamento. 
Figura 05. Efluente tratado biologicamente e após cada etapa de tratamento

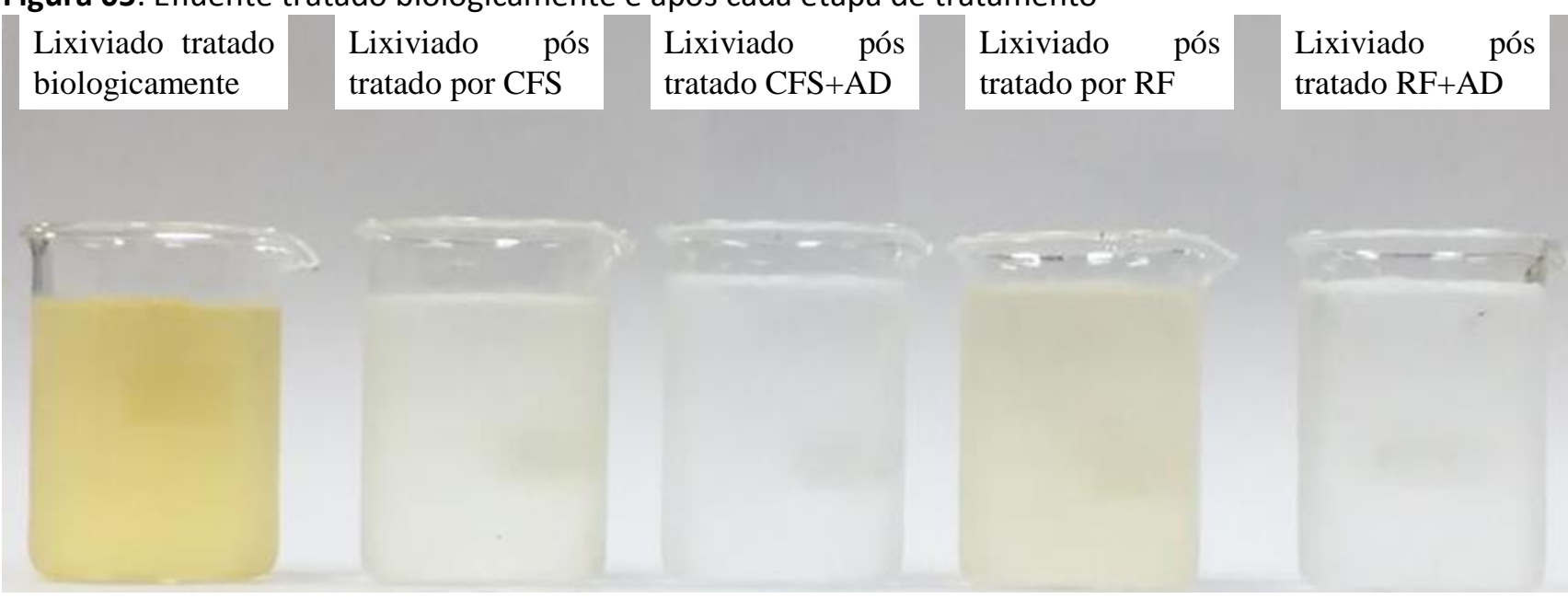

Fonte: Os autores, 2020.

Com relação a cor verdadeira, o efluente pós-tratado por ciclo completo submetido já apresentava valor inicial $0 \mathrm{uH}$ enquanto a adsorção do efluente inicialmente tratado por reação de Fenton apresentou uma remoção de $84,0 \%$ da cor verdadeira.

Em relação à remoção de $\mathrm{DQO}$ a adsorção foi capaz de remover $76,9 \%$ do efluente pós-tratado por coagulaçãofloculação-sedimentação, e $37,3 \%$ para oxidação de Fenton.
A turbidez teve um aumento de 1,3 para 2,7 UNT na CFS associada à adsorção e de 2,5 para 3,8 UNT na reação de Fenton + adsorção, uma justificativa para o aumento da turbidez é a perda de carvão durante a adsorção.

A Tabela 09 apresenta eficiência de remoção de matéria orgânica correlacionada à cor verdadeira e DQO após o lixiviado ser submetido à adsorção.

Tabela 08. Características iniciais do lixiviado e após tratamentos de coagulação-floculação-sedimentação, Fenton e Fenton + adsorção

\begin{tabular}{|c|c|c|c|c|c|}
\hline Caracterização físico-química & $\begin{array}{c}\text { Lixiviado tratado } \\
\text { biologicamente }\end{array}$ & $\begin{array}{l}\text { Lixiviado pós-tratado por } \\
\text { coagulação-floculação- } \\
\text { sedimentação } \\
\end{array}$ & $\begin{array}{l}\text { Lixiviado pós-tratado por } \\
\text { coagulação-floculação- } \\
\text { sedimentação e adsorção }\end{array}$ & $\begin{array}{c}\text { Lixiviado pós- } \\
\text { tratado por reação } \\
\text { de Fenton } \\
\end{array}$ & $\begin{array}{c}\text { Lixiviado pós-tratado } \\
\text { por reação de Fenton e } \\
\text { adsorção } \\
\end{array}$ \\
\hline $\mathrm{pH}$ & 7,6 & 4,5 & 6,3 & 4,0 & 5,9 \\
\hline turbidez (UNT) & 29,6 & 1,3 & 2,7 & 2,5 & 3,8 \\
\hline cor aparente $(\mathrm{uH})$ & 1241,0 & 20,9 & 8,3 & 108,6 & 66,9 \\
\hline cor verdadeira $(\mathrm{uH})$ & 447,0 & $<\mathrm{L} . \mathrm{Q}$. & $<\mathrm{L} . \mathrm{Q}$. & 54,3 & 8,4 \\
\hline sólidos totais (mg.L $\mathrm{L}^{-1}$ ) & 1,6 & 2,0 & 1,9 & 2,1 & 1,8 \\
\hline sólidos totais fixos $\left(\mathrm{mg} . \mathrm{L}^{-1}\right)$ & 1,3 & 1,7 & 1,6 & 1,6 & 1,3 \\
\hline Nitrogênio de Kjeldahl Total (mg.L $\left.{ }^{-1}\right)$ & 50,2 & 11,8 & 7,8 & 11,0 & 8,6 \\
\hline Nitrogênio amoniacal (mg. $\left.\mathrm{L}^{-1}\right)$ & 47,0 & 7,8 & 2,0 & 5,9 & 2,0 \\
\hline Demanda Química de Oxigênio (mg. $\left.\mathrm{L}^{-1}\right)$ & 280,0 & 130,0 & 30,0 & 92,5 & 58,0 \\
\hline
\end{tabular}

Fonte: Os autores, 2020. 
Tabela 09. Características iniciais, condição de adsorção, eficiência de remoção tratamento por adsorção.

\begin{tabular}{|c|c|c|c|c|}
\hline Etapa de tratamento & Características iniciais & Adsorvente & Eficiência de remoção & Referência \\
\hline $\begin{array}{l}\text { Pós-tratamento } \\
\text { por reação de Fenton }\end{array}$ & $\begin{array}{c}\mathrm{pH} 8,5 \\
\text { DQO } 8000 \mathrm{mg} \mathrm{O}_{2} \mathrm{~L}^{-1}\end{array}$ & CAG (casca de coco) & DQO $58 \%$ & $\begin{array}{l}\text { KURNIAWAN } \\
\text { et al., } 2009\end{array}$ \\
\hline $\begin{array}{l}\text { Pós-tratamento } \\
\text { biológico }\end{array}$ & $\begin{array}{l}\mathrm{pH} \mathrm{9,1;} \mathrm{Cor} \mathrm{verdadeira} 110 \mathrm{uH} \\
\text { DQO } 104 \mathrm{mg} \mathrm{O}_{2} \mathrm{~L}^{-1}\end{array}$ & CAG & $\begin{array}{c}\text { Cor verdadeira } 100 \% \\
\text { DQO } 82,5 \%\end{array}$ & $\begin{array}{l}\text { MENDES } \text { et al. } \\
2013\end{array}$ \\
\hline $\begin{array}{c}\text { Pós-tratamento por } \\
\text { coagulação-floculação- } \\
\text { sedimentação }\end{array}$ & $\begin{array}{c}\text { pH } 7 \\
\text { DQO 2500 a } 3000 \mathrm{mg} \mathrm{O}_{2} \mathrm{~L}^{-1}\end{array}$ & $18 \mathrm{~g} \mathrm{~L}^{-1}$ & $\begin{array}{l}\text { Cor } 29 \% \text { a } 30 \% \\
\text { DQO } 29 \text { a } 38 \%\end{array}$ & GUNES, 2014 \\
\hline $\begin{array}{l}\text { Pós-tratamento } \\
\text { biológico }\end{array}$ & $\begin{array}{l}\mathrm{pH} \text { 9,7; Cor verdadeira } 3386 \mathrm{uH} \\
\text { DQO } 2022 \mathrm{mg} \mathrm{O}_{2} \mathrm{~L}^{-1}\end{array}$ & $\begin{array}{c}\text { Carvão ativado } \\
\text { (endocarpo do coco) }\end{array}$ & $\begin{array}{c}\text { Cor verdadeira } 94 \text { a } 100 \% \\
\text { DQO } 45-76 \%\end{array}$ & $\begin{array}{l}\text { KAWAHIGASHI } \\
\text { et al. , } 2014\end{array}$ \\
\hline Tratamento & $\begin{array}{c}\mathrm{pH} 8,4 \\
\text { DQO } 3378 \mathrm{mg} \mathrm{O}_{2} \mathrm{~L}^{-1}\end{array}$ & CAP $5 \mathrm{~g} \mathrm{~L}^{-1}$ & DQO 69\% & $\begin{array}{l}\text { VASCONCELO } \\
\text { S et al. , } 2017\end{array}$ \\
\hline $\begin{array}{c}\text { Pós-tratamento por } \\
\text { coagulação-floculação- } \\
\text { sedimentação }\end{array}$ & $\begin{array}{c}\text { pH 6,3; Cor verdadeira < LQ } \\
\text { DQO } 130 \mathrm{mg} \mathrm{O}_{2} \mathrm{~L}^{-1}\end{array}$ & CAG (osso) & DQO $76,9 \%$ & $\begin{array}{l}\text { Este trabalho, } \\
2020\end{array}$ \\
\hline $\begin{array}{l}\text { Pós-tratamento } \\
\text { por reação de Fenton }\end{array}$ & $\begin{array}{c}\text { pH 5,9; Cor verdadeira 54,3 uH } \\
\text { DQO 92,5 } \mathrm{mg} \mathrm{O}_{2} \mathrm{~L}^{-1}\end{array}$ & CAG (osso) & $\begin{array}{c}\text { Cor verdadeira } 84,5 \% \\
\text { DQO } 37,3 \%\end{array}$ & $\begin{array}{l}\text { Este trabalho, } \\
\quad 2020\end{array}$ \\
\hline
\end{tabular}

Fonte: Os autores, 2020.

\subsection{Curva de ruptura}

A curva de ruptura foi elaborada utilizando o lixiviado tratado para a obtenção da capacidade máxima de adsorção do adsorvente selecionado (CAG 2). A Figura 06 representa a curva de ruptura do CAG 2 .

A massa de CAG 2 utilizada foi 17,81 g para $12,25 \mathrm{~L}$ até atingir um percentual de cor aparente residual em relação à cor aparente inicial de aproximadamente 100,0 \%. Considerando uma eficiência mínima de 30\% de remoção de cor aparente após 55 horas, para o tratamento de $1 \mathrm{~L}$ de lixiviado foi necessária uma massa de 1,72g.

Figura 06. Curva de ruptura do carvão ativado granular selecionado - CAG2 para cor aparente.

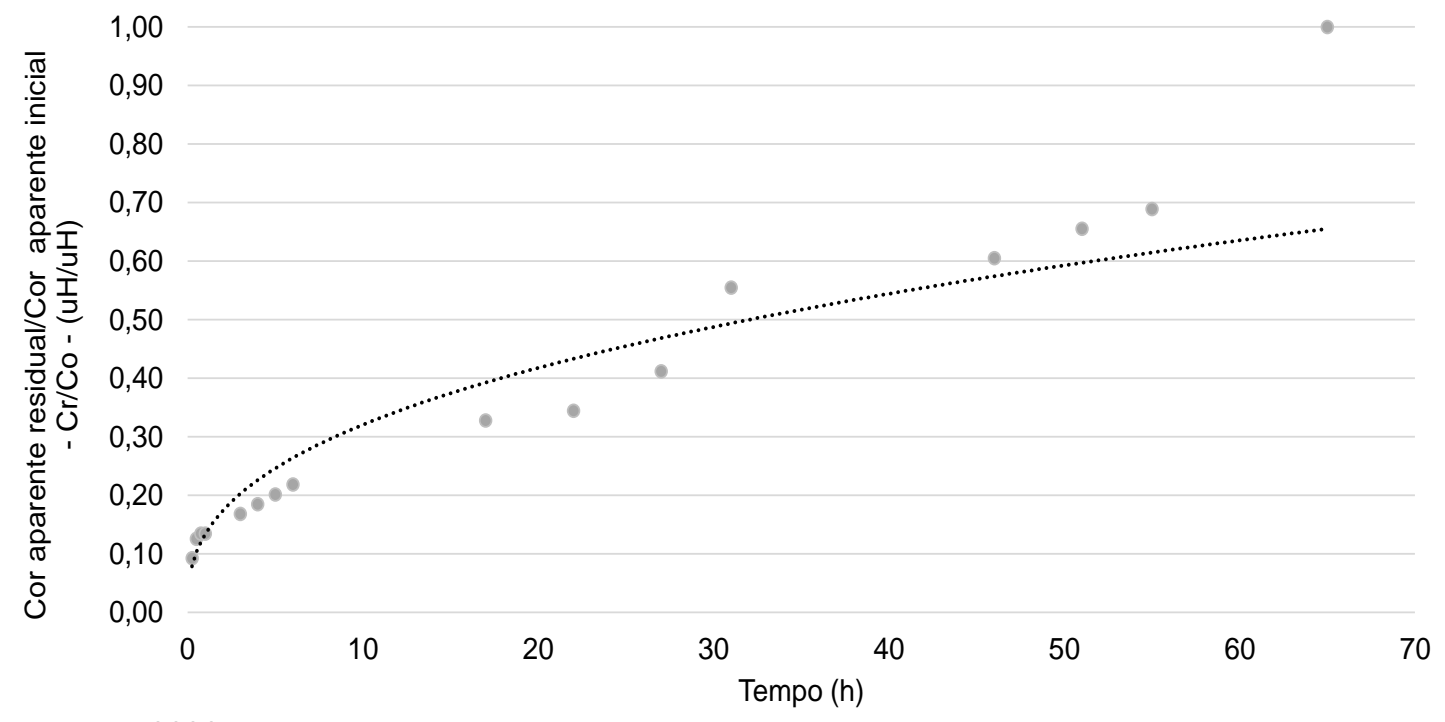

Fonte: Os autores, 2020.

\subsection{Bioensaio com Artemia salina}

O ensaio foi realizado para a obtenção do valor de concentração letal responsável pela mortalidade $50,0 \%$ dos organismos na presença do lixiviado nas diferentes amostras em estudo. Para isso, foi utilizado o software 
Trimmed Spearman-karber Method. A tabela 10 apresenta a toxicidade presente no lixiviado tratado biologicamente e após cada pós-tratamento. Após decorrer 24 horas foi analisado que as amostras do póstratamento por reação de Fenton possui maior toxicidade que o lixiviado tratado biologicamente, apresentando uma concentração letal média $\left(\mathrm{CL}_{50}\right)$ de $77,2 \%$, possivelmente devido aos produtos químicos $\mathrm{H}_{2} \mathrm{O}_{2}$ e $\mathrm{Fe}^{2+}$ terem reagido e gerado uma toxicidade ao efluente que inicialmente não existia. Apesar disso, após o emprego da adsorção no efluente tratado por reação de Fenton não apresenta toxicidade. As amostras pós-tratamento por CFS apresentam uma baixa toxicidade, no entanto não foi possível determinar o $\mathrm{CL}_{50}$.

O lixiviado tratado biologicamente após 48 horas manifestou toxicidade, porém, não foi possível determinar o $\mathrm{CL}_{50}$ da

Tabela 10. Efeito imobilidade/letalidade da Artemia salina para os efluentes tratado biologicamente e póstratados por ciclo completo, ciclo completo e adsorção, oxidação de Fenton e oxidação de Fenton e adsorção.

\begin{tabular}{|c|c|c|c|}
\hline \multirow[b]{2}{*}{ Amostras } & \multicolumn{3}{|c|}{ Artemia salina } \\
\hline & Diluição (\%) & $\begin{array}{l}\text { Efeito máximo } \\
\text { observado }(\%)\end{array}$ & Toxicidade \\
\hline Lixiviado tratado biologicamente & $50,60,70,75,80$ e 90 & $\begin{array}{c}\text { 24h: } 0,0 \\
48 h: 51,9\end{array}$ & $\begin{array}{l}C L_{50-24 h}-N T \\
C L_{50-48 h}-N D \\
\end{array}$ \\
\hline $\begin{array}{l}\text { Lixiviado pós-tratado por coagulação-floculação- } \\
\text { sedimentação }\end{array}$ & $50,60,70,75,80$ e 90 & $\begin{array}{l}24 h: 11,4 \\
48 h: 44,4 \\
\end{array}$ & $\begin{array}{l}C L_{50-24 h}-N D \\
C L_{50-48 h}-N D\end{array}$ \\
\hline $\begin{array}{l}\text { Lixiviado pós-tratado por coagulação-floculação- } \\
\text { sedimentação e adsorção }\end{array}$ & $50,60,70,75,80$ e 90 & $\begin{array}{c}\text { 24h: } 5,4 \\
48 h: 40,0\end{array}$ & $\begin{array}{l}\mathrm{CL}_{50-24 h}-\mathrm{NT} \\
\mathrm{CL} \mathrm{L}_{50-48 \mathrm{~h}}-\mathrm{ND}\end{array}$ \\
\hline Lixiviado pós-tratado por reação de Fenton & $50,60,70,75,80$ e 90 & $\begin{array}{l}24 h: 100,0 \\
48 h: 100,0\end{array}$ & $\begin{array}{l}\mathrm{CL}_{50-24 h}-77,2 \% \\
\mathrm{CL}_{50-48 h}-80,9 \% \\
\end{array}$ \\
\hline Lixiviado pós-tratado por reação de Fenton e adsorção & $50,60,70,75,80$ e 90 & $\begin{array}{l}24 \mathrm{~h}: 0,0 \\
48 \mathrm{~h}: 0,0\end{array}$ & $\begin{array}{l}\mathrm{CL}_{50-24 h}-\mathrm{NT} \\
\mathrm{CL}_{50-48 h}-\mathrm{NT}\end{array}$ \\
\hline
\end{tabular}

Fonte: Os autores, 2020.

\section{A Resolução CEMA 82/2010} determina como condição de ecotoxicidade para lançamento de efluentes em corpos hídricos FT8, apesar das amostras analisadas apresentarem toxicidade todas se enquadram a este parâmetro.

\section{CONSIDERAÇÕES FINAIS}

O pós-tratamento por coagulaçãofloculação-sedimentação apresentou remoção superior a 98,9\% de cor verdadeira amostra. A toxicidade do lixiviado póstratado por reação de Fenton aumentou após 48 horas, atingindo $\mathrm{CL}_{50}$ de $80,9 \%$, valor maior do que observado no lixiviado bruto, isso se deve ao maior tempo de exposição da amostra e aos fatores já citados anteriormente.

A coagulação-floculação-sedimentação em 48 horas apresentou toxicidade no efluente, porém não foi possível calcular o $\mathrm{CL}_{50}$. A toxicidade obtida pode ser justificada pelos produtos químicos utilizados para realização da coagulação química e residuais de metais e cloretos provenientes do coagulante químico (cloreto férrico) empregado neste pós-tratamento (KAWAHIGASHI et al., 2013). O emprego da adsorção apenas foi capaz de remover a toxicidade do lixiviado pós-tratado por reação de Fenton. 
reação de Fenton, se enquadram nos parâmetros de descarte em corpos hídricos de 75 uH das Resoluções CONAMA 357/05 e 430/11.

A coagulação-floculação-sedimentação apresentou melhor desempenho na remoção de cor verdadeira quando comparada à reação de Fenton, porém, para remoção de $\mathrm{N}$ amoniacal, NKT e DQO, a RF obteve melhores resultados.

A CFS e RF seguidas de adsorção propiciaram remoções de $74,4 \%$ e $66,1 \%$ de $\mathrm{N}$-amoniacal, $76,9 \%$ e $37,3 \%$ de DQO, respectivamente. Apesar da eficiência para remoção de $\mathrm{N}$-amoniacal e DQO, após a adsorção foi observada turbidez residual superior a inicial, possivelmente devido à perda de carvão ativado no efluente durante a adsorção.

O bioensaio com a Artemia salina demonstrou baixa toxicidade para o lixiviado tratado biologicamente. Após RF foi observado efeito tóxico em 24 e 48 horas. 0 emprego da adsorção após o pós-tratamento de Fenton foi capaz de remover a toxicidade deste efluente.

Dessa forma, os pós-tratamentos por RF seguido de adsorção e CFS seguido de adsorção foram eficazes na remoção de parâmetros físico-químicos avaliados neste trabalho, possibilitando a destinação final desse efluente de maneira ambientalmente adequada. 


\section{REFERÊNCIAS}

ABNT. Associação Brasileira de Normas Técnicas. Ecotoxicologia aquática - Toxicidade aguda - Método de ensaio com Artemia sp. (Crustacea, Brachiopoda): NBR 16530. Rio de Janeiro, RJ, 2016. 16 p.

APHA. Standard methods for the examination of water and wastewater. American Public Health Association (APHA), American Water Works Association (AWWA) e Water Environment Federation (WEF), 2018.

BRASIL. Ministério do Meio Ambiente. Conselho Nacional de Meio Ambiente. Resolução $n^{\circ}$ 430, 13 de maio de 2011. Dispõe sobre as condições e padrões de lançamento de efluentes, complementa e altera a Resolução $n^{\circ}$ 357, de 17 de março de 2005, do Conselho Nacional do Meio Ambiente CONAMA. Brasília: MMA, 2011.

BRASIL. Ministério do Meio Ambiente. Conselho Nacional de Meio Ambiente. Resolução $n^{\circ}$ 357, 17 de março de 2005. Dispõe sobre a classificação dos corpos de água e diretrizes ambientais para o seu enquadramento, bem como estabelece as condições e padrões de lançamento de efluentes, e dá outras providências. Brasília: MMA, 2005.

CASTILHOS JUNIOR, A.; DALSASSO, R.; ROHERS, F. Pré-tratamento de lixiviados de aterros sanitários por filtração direta ascendente e coluna de carvão ativado. Engenharia Sanitária e Ambiental, Rio de Janeiro, v. 15, n. 4, p. 385-392, 2010. https://doi.org/10.1590/S1413-

$\underline{41522010000400011}$

COSTA, A.; ALFAIA, R.; CAMPOS, J. Landfill leachate treatment in Brazil-An overview. Journal of Environmental Management, v. 232, p. 110-116, 2019. https://doi.org/10.1016/i.jenvman.2018.11.006

DA SILVA, C; LANGE, M.; FERREIRA, C.; AMARAL, M.; ARTHUZO, P. Avaliação da composição orgânica de percolado submetido aos processos Fenton e Foto-Fenton. In: CONGRESSO INTERAMERICANO DE INGENIERIA SANITÁRIA Y AMBIENTAL, 30., 2006, Punta del Este - Uruguay. Anais [...]. Punta del Este, 2006.

DENG, Y. Physical and oxidative removal of organics during Fenton treatment of mature municipal landfill leachate. Journal of Hazardous Materials, v. 146, p. 334-340, 2007.

https://doi.org/10.1016/j.jhazmat.2006.12.026

FELICI, E.; KURODA, E.; YAMASHITA, F.; SILVA, $S$. Remoção de carga orgânica recalcitrante de lixiviado de resíduos sólidos urbanos prétratado biologicamente por coagulação química-floculação-sedimentação. Engenharia Sanitária e Ambiental, v. 18, n. 2, p. 177-184, $2013 . \quad$ https://doi.org/10.1590/S1413$\underline{41522013000200010}$

FUKUMOTO, A.; KURODA, E. Seleção de carvões ativados para adsorção de microcistinas. Engenharia Sanitária e. Ambiental, Rio de Janeiro, v. 24, n. 2, p. 295304, abr. 2019. https://doi.org/10.1590/s1413$\underline{41522019183445}$

GUNES, E. Seasonal characterization of landfill leachate and effect of seasonal variations on treatment processes of coagulation/flocculation and adsorption. Polish Journal of Environmental Studies, v. 23, n. 4, 2014.

HUOSHENG, L.; SHAOQI, Z.; YANBO, S.; JIANG, L. Application of response surface methodology to the advanced treatment of biologically stabilized landfill leachate using Fenton's reagent. Waste Management, v. 30, p. 2122-2129, 2010. https://doi.org/10.1016/j.wasman.2010.03.036

KANG, Y. W.; HWANG, K. Effects of reaction conditions on the oxidation efficiency in the Fenton process. Water Research, v. 34, p. 
2786-2790,

https://doi.org/10.1016/S0043-

1354(99)00388-7

KAWAHIGASHI, F.; KOGA, D.; KURODA, E. Ensaio de ecotoxicidade utilizando Pseudokirchneriella subcapitata, Ceriodaphnia dubia, Daphnia magna e Artemia salina para caracterização de lixiviado proveniente de aterro sanitário. Periódico Eletrônico Fórum Ambiental da Alta Paulista, v. 9, no 11. 2013. https://doi.org/10.17271/198008279112013676

KAWAHIGASHI, F.; MENDES, M.; ASSUNÇÃO JUNIOR, V.; GOMES, V.; FERNANDES, F.; HIROOKA, E.; KURODA, E. Pós-tratamento de lixiviado de aterro sanitário com carvão ativado. Engenharia Sanitária e Ambiental, v. 19, n. 3, p. 235-244, 2014. https://doi.org/10.1590/S141341522014019000000652

KURNIAWAN, T.; LO, W. Removal of refractory compounds from stabilized landfill leachate using an integrated $\mathrm{H}_{2} \mathrm{O}_{2}$ oxidation and granular activated carbon (GAC) adsorption treatment. Water research, v. 43, n. 16, p. 4079-4091, 2009. https://doi.org/10.1016/i.watres.2009.06.060

LANGE, L. C.; ALVES, J. F.; AMARAL, M. C. S.; MELO JÚNIOR, W. R. Tratamento de lixiviado de aterro sanitário por processo oxidativo avançado empregando reagente de Fenton. Engenharia Sanitária e Ambiental, v. 11, p. 175-183, 2006. https://doi.org/10.1590/S1413$\underline{41522006000200011}$

MALER, C. L.; SIMIONATI, L.; SANTOS, T.; FERNANDES, F. Sequência de tratamentos para lixiviado de aterro sanitário utilizando os processos físico-químico convencional e Fenton como pós-tratamento. Revista DAE, v. 63, p. 47-57, 2015. https://doi.org/10.4322/dae.2014.145

MELLO, V.; ABREU, J.; FERREIRA, J.; JUCÁ, J. SOBRINHO, $M$. Variáveis no processo de coagulação/floculação/decantação de lixiviados de aterros sanitários urbanos. Revista Ambiente e Água, v. 7, n. 2, 2012. https://doi.org/10.4136/ambi-agua.861 MENDES, M.; KAWAHIGASHI, F.; KURODA, E. Adsorção de matéria orgânica em carvão ativado granular no pós tratamento de lixiviado de aterro. Periódico Eletrônico Fórum Ambiental da Alta Paulista, v. 9, n. 11, 2013.

https://doi.org/10.17271/198008279112013676

MORAVIA, W.; LANGE, L.; AMARAL, M. Avaliação da microfiltração para remoção do lodo gerado no processo oxidativo avançado empregando $o$ reagente de Fenton no tratamento de lixiviado de aterro sanitário. Engenharia Sanitária Ambiental, v. 16, n. 4, p. 379-386, 2011. https://doi.org/10.1590/S1413$\underline{41522011000400009}$

NASCENTES, A.; NASCIMENTO, M.; BRASIL, F.; CAMPOS, J.; FERREIRA, J. Tratamento combinado de lixiviado de aterro sanitário e esgoto doméstico-Aspectos operacionais e microbiológicos. Revista Eletrônica TECCEN, v. $8, \quad$ n. $1, \quad$ p. 05-12, 2015. https://doi.org/10.21727/198409932015.tecc en.v8i1.05-12

NOGUEIRA, R.; TROVÓ, A.; SILVA, M.; VILLA, R. et al. Fundamentos e aplicações ambientais dos processos Fenton e foto-Fenton. Química nova, v. 30, n. 2, p. 400-408, 2007. https://doi.org/10.1590/S0100$\underline{40422007000200030}$

PARANÁ. Conselho Estadual do Meio Ambiente. Resolução 081/2010 - CEMA. Dispõe sobre critérios e padrões de ecotoxicidade para o controle de efluentes líquidos lançados em águas superficiais no Paraná. Curitiba, 2010.

PETROBRÁS. N-2588. Determinação da Toxicidade Aguda de Agentes Tóxicos em Relação à Artemia sp. 1996. 12 p. 
PEYRAVI, M.; JAHANSHAHI, M.; ALIMORADI, M.; GANJIAN, E. Old landfill leachate treatment through multistage process: membrane adsorption bioreactor and nanofiltration. Bioprocess and biosystems engineering, v. 39, n. 12, p. 1803-1816, 2016. https://doi.org/10.1007/s00449-016-1655-0 POZZETTI, J.; ASSUNÇÃO JUNIOR, V.; BATISTA, A.; KURODA, E. Seleção de carvão ativado pulverizado para pós-tratamento de lixiviado de aterros sanitário. Fórum Ambiental da Alta Paulista, v. 9, n. 11, 2013. https://doi.org/10.17271/198008279112013693

QUEIROZ, L.; AMARAL, M.; MORITA, D.; YABRODI, S.; SOBRINHO, P. Aplicação de processos físico-químicos como alternativa de pré e pós-tratamento de lixiviados de aterros sanitários. Engenharia Sanitária Ambiental, Rio de Janeiro, v. 16, n. 4, p. 403410, 2011. https://doi.org/10.1590/S1413$\underline{41522011000400012}$

RODRIGUES, C.; LOPES, D. Aplicação do reagente de Fenton em lixiviado de aterro sanitário tratado biologicamente, visando a remoção de matéria orgânica recalcitrante. In: FÓRUM INTERNACIONAL DE RESÍDUOS SÓLIDOS 4., - 2013, Porto Alegre. Anais [...]. Porto Alegre, 2013. p. 10.

SERAFIM, A.; GUSSAKOV, K; SILVA, F.; CONEGLIAN, C.; BRITO, N.; DRAGON, G. Chorume, impactos ambientais e possibilidades de tratamento. In: III Fórum de Estudos Contábeis. Rio Claro: Centro Superior de Educação Tecnológica; 2003. p. 6-7.

SILVA, C.; LANGE, L.; AMARAL, M.; ARTHUZO, P. Aplicação dos processos Fenton e fotoFenton no tratamento de percolados de aterros sanitários. In: CONGRESSO BRASILEIRO DE ENGENHARIA QUÍMICA (COBEQ). 16., 2006. p. 1-2.

SNIS -Sistema Nacional de Informações sobre Saneamento. Diagnóstico do Manejo de Resíduos Sólidos Urbanos, 2017.
TARTARI, L. Avaliação do processo de tratamento do chorume do aterro sanitário de novo Hamburgo. Revista eletrônica Liberato, v; 6, n. 5, 2005.

VASCONCELOS, D.; SILVA, L.; GUERRA, I.; CAMPOS, J. Estudo da tratabilidade de lixiviado gerado em um aterro controlado. Ambiente \& Água - An Interdisciplinary Journal of Applied Science, v. 12, n. 3, p. 457467, 2017. https://doi.org/10.4136/ambiagua.1957

YANYU, W.; FANGHUI, Q.; SHAOQUI, Z.; HUAPING, P.; YANGLAN, L.; YIMING, L. Removal of humic substances from landfill leachate by Fenton oxidation and coagulation. Process safety and environmental protection, v. $88, \quad$ p. 276-284, 2010. https://doi.org/10.1016/j.psep.2010.03.002 